\title{
THE IMPACT OF DAMAGE IN INCONEL 718 ON HARDNESS MEASURED BY THE VICKERS METHOD
}

\author{
Maciej Malicki \\ Bartosz Madejski \\ Institute of Aviation, Al. Krakowska 110/114, 02-256 Warsaw, Poland \\ maciej.malicki@ilot.edu.pl, bartosz.madejski@ilot.edu.pl
}

\begin{abstract}
To prevent failure of machine components it is necessary to measure material damage generated in a component throughout its entire lifetime. Damage can be quantified by means of damage parameters. This paper considers the usefulness of hardness measurements to evaluate damage parameter in Inconel 718. Vickers hardness tests were performed on a specimen with a variable cross section area after tensile testing. The specimen's geometry enabled the evaluation of damage parameter in respect of hardness measurements made on one individual specimen.
\end{abstract}

Keywords: Damage parameter, Vickers hardness, Inconel 718, Tensile test.

\section{INTRODUCTION}

To avoid material failure engineers use damage numerical models [1] e.g. the GursonTvergaard-Needleman model (GTN), and the Jonson-Cook and Lemaitre models [2]. These models refer to microscopical damage in the material structure related to the plastic deformation of the material caused by macroscopically applied stress. These structural changes in the deformed material affect its mechanical properties and have a great impact on the safety and life prediction of the working component. Quantitative evaluation of material damage can be done using the damage parameter. According to the model proposed by Katchanov isotropic damage can be described as a reduction of the specimen's cross section area, which is related to the presence of microvoids in the material. The damage parameter can be then defined as a scalar and expressed by the equation [3]:

$$
D=\frac{S_{D}}{S}
$$

Where $S$ is the surface of the representative volume element (RVE) cross section, $S_{D}$ is damaged surface of RVE cross section.

The scalar damage parameter $(D)$ can be evaluated in many ways by means of material properties sensitive to plastic deformation of the material. One such property is hardness.

The hardness test is one of the easiest and most widely used mechanical tests used for evaluating the properties of metals. Hardness can be described as the resistance of the material to permanent deformation caused by an indenter which is pressed into the material with a specified force. According to Lemaitre, for isotropic and kinematic hardening the yield stress in damaged material is formulated as [3]:

$$
\sigma_{s}=\left(\sigma_{y}+X+R\right) \cdot(1-D)
$$


Where $\sigma_{y}$ is yield strength, $X$ is back stress, $R$ is stress due to isotropic hardening.

In the same work [3], Lemaitre presents the conclusion that the hardness of a material can be expressed as the linear function $\sigma_{\mathrm{s}}$ :

$$
H=k^{\prime} \cdot \sigma_{s}
$$

Hardness in any region of damaged material will be expressed as:

$$
H=k^{\prime} \cdot\left(\sigma_{y}+X+R\right) \cdot(1-D)
$$

According to Equation (4) the damage parameter in respect of material hardness $\left(D_{H}\right)$ can be expressed as:

$$
D_{H}=1-\frac{H}{H^{*}}
$$

Where $H^{*}$ is a hypothetical reference hardness of the tested material that has been plastically deformed without any damage.

\section{METHODOLOGY}

Hardness tests were performed on plastically deformed specimens in order to verify Equation (5).

\section{Arrangements prior to Hardness Test}

For the tests, Inconel 718 was used. It is a Nickel-based alloy (Table 1) used for heat resistant components such as compressor blades in a jet engine.

Table 1. Chemical composition of Inconel 718 selected for tests

\begin{tabular}{|c|c|c|c|c|c|c|}
\hline \multicolumn{7}{|c|}{ Chemical elements [wt. \%] } \\
\hline $\mathrm{Ni}$ & $\mathrm{Cr}$ & $\mathrm{Nb}$ & $\mathrm{Mo}$ & $\mathrm{Ti}$ & $\mathrm{Al}$ & $\mathrm{Fe}$ \\
\hline $50.0-55.0$ & $17.0-21.0$ & $4.75-5.50$ & $2.8-3.3$ & $0.65-1.15$ & $0.20-0.80$ & Balance \\
\hline
\end{tabular}

The specimen for the tensile test was prepared from the annealed rolled sheet. Metallography inspection shows that the material's structure consists of equiaxial grains and carbides particles (Figure 1).

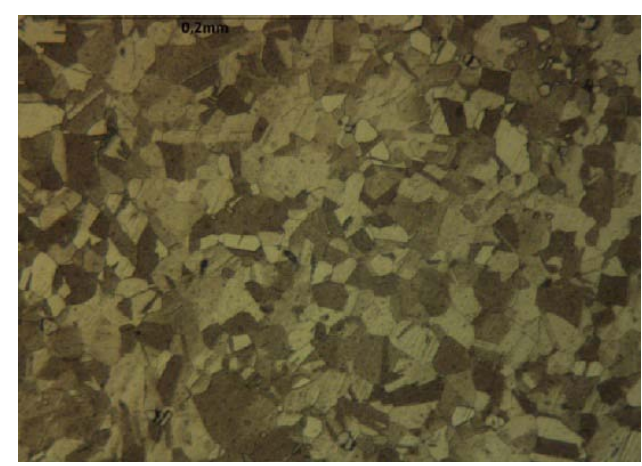

Figure 1. Structure of tested Inconel 718

Tensile test was conducted on a specimen with a variable cross-section area (Figure 2) [4] in a MTS testing machine (model MTS 318.10) with a force transducer (Made: MTS model no. 661.20F-03). The specimen's geometry is responsible for continuous deformation after the tensile test, ranging from plastic strain associated with yield strength to plastic strain associated with ultimate strength. 


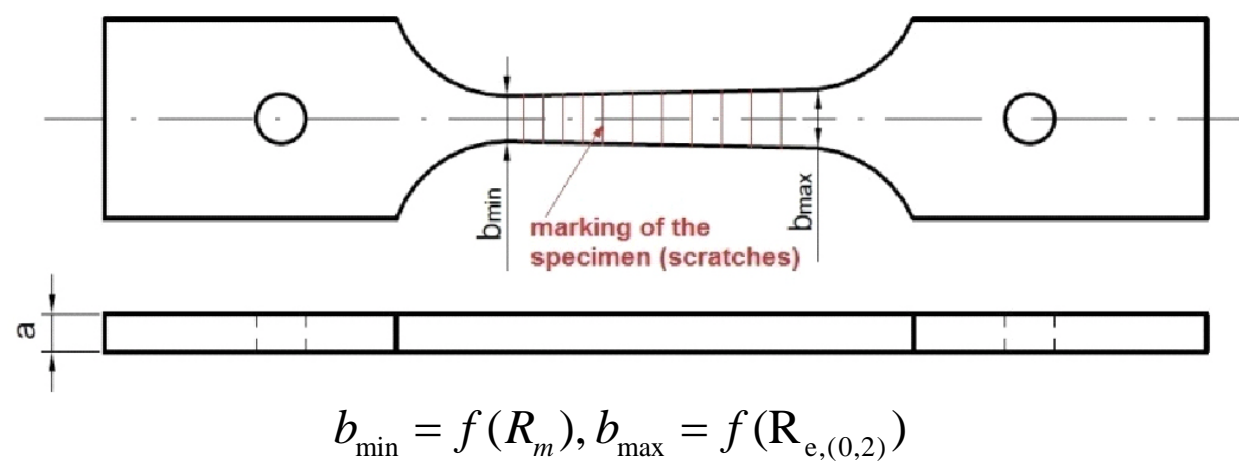

Figure 2. Specimen geometry used for tests

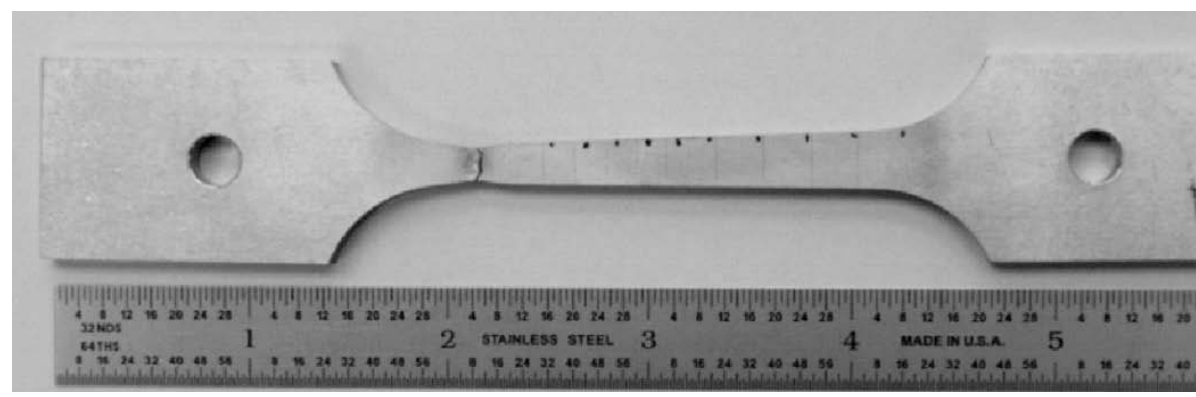

Figure 3. Specimen after tensile test
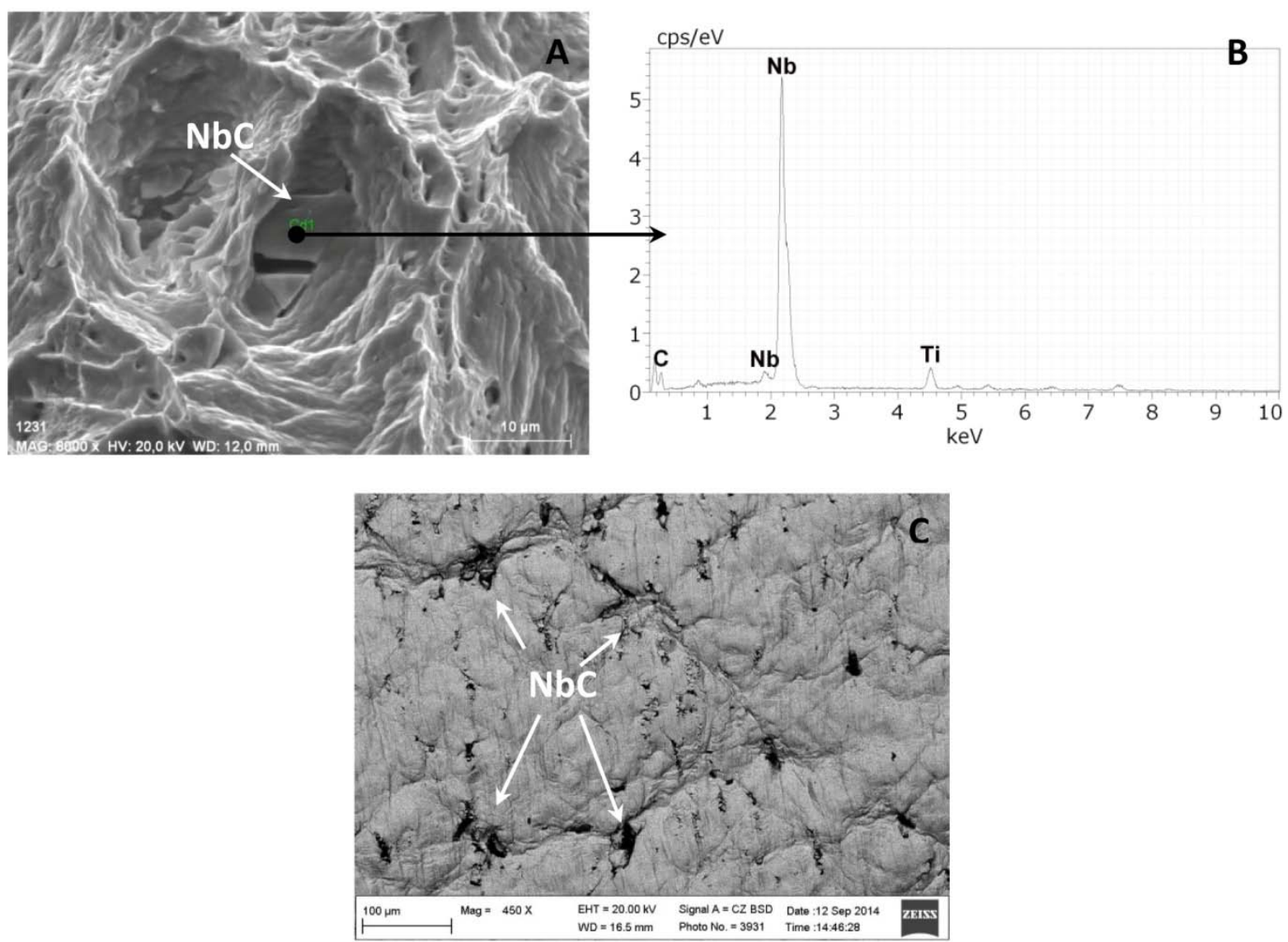

Figure 4. SEM inspection of the specimen after tensile test. SEM-SE image shows the fracture surface with carbides at the bottom of the dimple (A).

EDX spectrum shows chemical composition of carbides $(B)$.

SEM-BSE image shows cracked carbides in the specimen's surface near the fracture (C). 
After the tensile test, the specimen (Figure 3) was inspected in a scanning electron microscope (SEM) (Made: CARL ZEISS model no. 25MA). The fracture's surface was ductile-type with dimple structure (Figure 4A).

There were cracked particles in the bottom of the dimple. Energy-dispersive X-ray spectroscopy (EDX) using a BRÜKER detector (model no. X Flash Detector 5010125 eV) was performed to determine the composition of these particles. The results showed that these particles consisted of Niobium (Nb), Carbon (C) and Titanium (Ti) (Figure 4B). It seems that the NbC primary carbides are quite often present in Inconel 718. As these NbC carbides are not aligned with the crystal structure of the matrix, they worsen mechanical properties of Inconel 718 [5].

Carbides of the same type were found in the specimen's surface (Figure 4C). They were cracked, detached from the matrix and in consequence created cavities in the material. The intensity of cracks and detachment were increasing with an increasing degree of plastic deformation. This type of damage occurs simultaneously with the plastic deformation of the matrix.

This type of damage is called Ductile Plastic Damage [6] and the failure mechanism can be associated with the forming and growth of the fracture's free surface on cracked NbC carbides and their debonding from the matrix.

For these reasons, it was assumed that D can be expressed by Equation (1) and DH can be evaluated according to Equation (5).

\section{Hardness Test}

After the SEM inspection, a piece of the material was cut out from the specimen reduction area (Figure 5). It was then ground and polished to prevent the deformed and damaged specimen's surface from affecting the hardness value. Hardness tests were conducted in selected areas in the specimen's width-height cross section in the tensile direction.

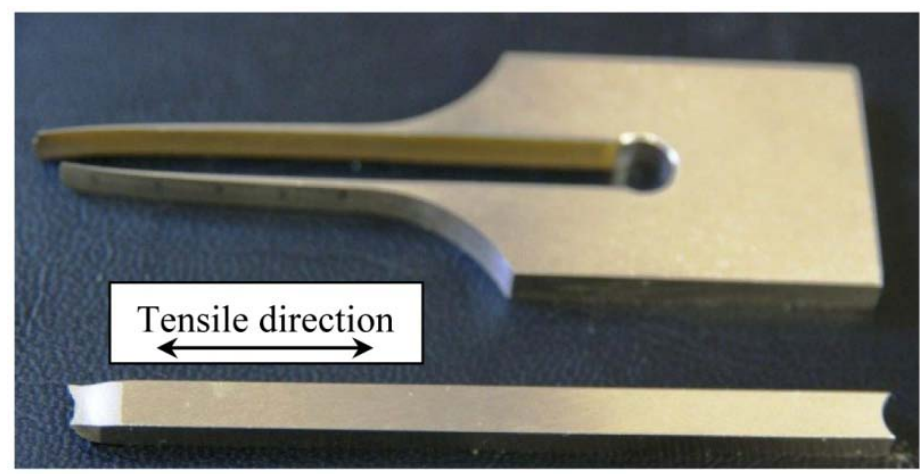

Figure 5. Specimen after tensile test prepared for hardness test

Hardness measurements were performed on a Vickers hardness test machine (Made: INNOVATEST, model no. NEXUS 4000). The measurement procedure was specified with respect to ASTM E384 [7]. 5 indentations were done in each selected area. Average hardness values calculated for each set of indentations (calculated from Equation (6)) were used for further investigation.

$$
H V=\frac{F}{A} \approx \frac{1.8544 F}{\sim d^{2}}
$$

where $F$ - is force applied to the intender, $A$ - is area of indentation, and $d$ is average length of the indentation's diagonals. 
The parameters of the test are presented in Table2. The force used has been chosen such as to achieve an indentation size corresponding to the representative volume element (RVE) (Figure 6). Also, for force equal to or greater than $10 \mathrm{kgf}$, the measured hardness value depended on the force applied to a small extent only (Figure 7). Prior to the tests, the measurements were made on the hardness reference test block 336.6HV10. Deviation from the reference value was lesser than $1.5 \%$

Table 2. Parameters of hardness test and measured value of hardness reference block

\begin{tabular}{|c|c|c|c|}
\hline $\begin{array}{c}\text { Force } \\
{[\mathrm{kgf}]}\end{array}$ & $\begin{array}{c}\text { DWEL } \\
\text { TIME }[\mathrm{s}]\end{array}$ & $\begin{array}{c}\text { MAGNIFICATION } \\
{[\mathrm{x}]}\end{array}$ & $\begin{array}{c}\text { MEASUREMENT ON HARDNESS } \\
\text { REFERENCE TEST BLOCK 336.6HV10 } \\
{[\text { HV10] }}\end{array}$ \\
\hline 10 & 10 & 20 & 332.3 \\
\hline
\end{tabular}

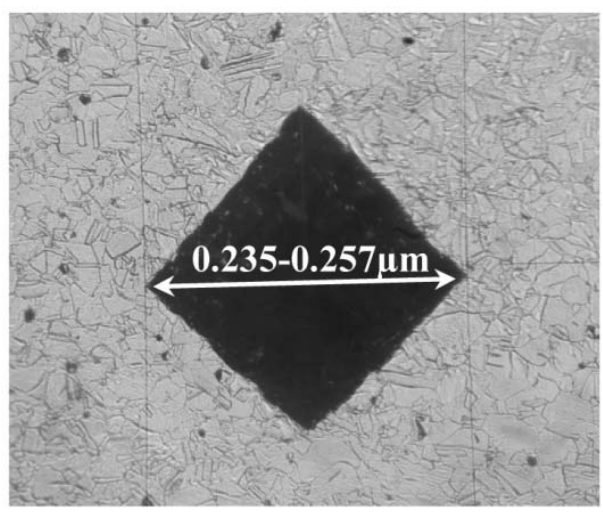

Figure 6. Indentation in tested Inconel 718 depends on the material's structure

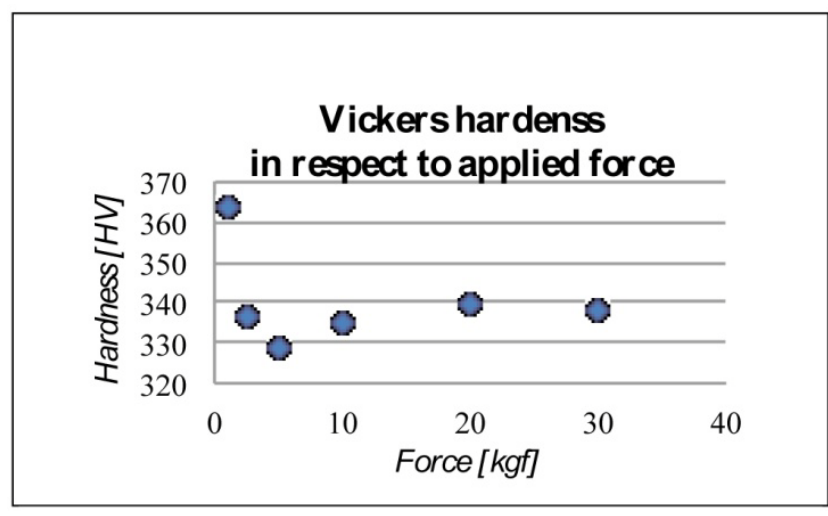

Figure 7. Hardness in relation to applied force

\section{RESULTS AND DISCUSSION}

The measurement results show that the average hardness value of the tested inconel 718 increases with increasing its plastic deformation (Figure 8). This is associated with strain hardening of the deformed material.

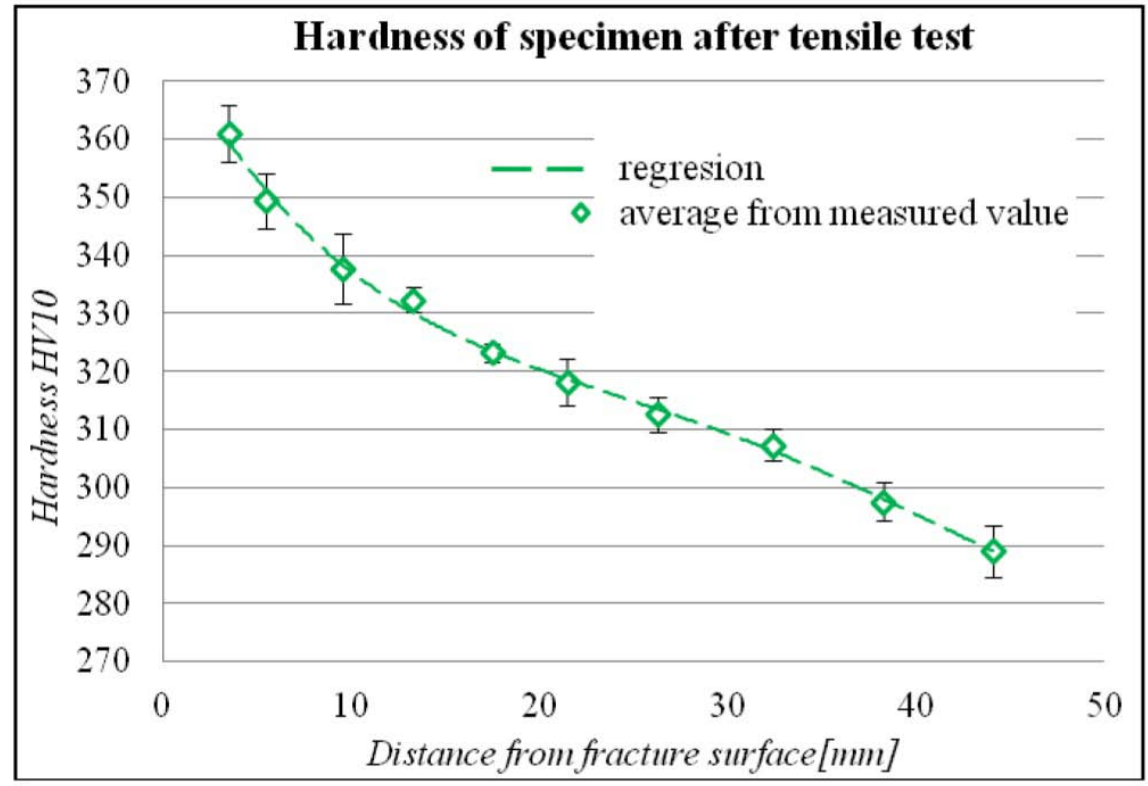

Figure 8. Hardness values for the specimen after tensile test 
To evaluate the damage parameter from Equation (5), reference hardness $\left(H^{*}\right)$ has to be found. It was done using the tensile test data based on the procedures described in [8]. According to the assumption contained in this paper it can be stated that:

$\frac{H V^{*}}{\tilde{\sigma}_{p}}=\frac{C_{H} \cdot\left(\widetilde{\varepsilon}_{p}\right)^{n}}{C_{R} \cdot\left(\widetilde{\varepsilon}_{p}\right)^{n}}=a$

Where $C_{H}, C_{R}$ and $a$ are the material parameters, $\tilde{\sigma}_{p}$ is hardening stress, $\widetilde{\varepsilon}_{p}$ is the plastic component of true strain, $n$ is the material constant known as the strain hardening exponent.

It was assumed that for small plastic strain the material's damage is negligible. It means that:

$$
H V^{*}=H V
$$

Combining Equation (7) and (8) the equation for $C_{H}$ can be expressed as:

$$
C_{H}=a \cdot C_{R}
$$

The parameter $C_{R}$ and $a$ can be found from the hardening stress- true strain curve determined from the tensile test data. After that the reference hardness of the tested material can be found from the equation:

$$
H V^{*}=C_{H} \cdot\left(\widetilde{\varepsilon}_{p}\right)^{n}
$$

In a specimen with a variable cross section area, hardening stress in function of true strain was determined only for the reference sections. These were marked on the specimen's surface prior to performing the tensile test. Assuming that the volume of the material doesn't change the plastic component of true strain in the reference sections, $\left(\widetilde{\varepsilon}_{p_{i}}\right)$ was calculated from the relation:

$$
\widetilde{\varepsilon}_{p_{i}}=-\left(\ln \frac{a_{i}}{a_{i_{o}}}+\ln \frac{b_{i}}{b_{i_{o}}}\right)
$$

Where $a_{i}, b_{i}$ are the specimen's width and thickness respectively in the reference sections after the tensile test; $a_{i 0}, b_{i 0}$ are width and thickness in the reference sections before the tensile test.

Hardening stress in the reference regions $\left(\tilde{\sigma}_{p_{i}}\right)$ was calculated from the relation:

$$
\tilde{\sigma}_{p_{i}}=\frac{F_{\max }}{a_{i} \cdot b_{i}}-\sigma_{y}
$$

Where $F_{\max }$ is maximum load applied to the specimen during the tensile test, and $\sigma_{y}$ is yield strength.

Power regression for the determined hardening stress-true strain values was done (Figure 9). The parameters $n$ and $C_{R}$ were found from the regression curve equation (Figure 10). It means that calculation for $\mathrm{H}^{*}$ can be performed now.

Hardness wasn't measured at the same places where reference hardness was calculated. Therefore, the approximation of the specimen's hardness value was done.

After that $D_{H}$ can be specified (Figure 11). The results show that the relation between $D_{H}$ value and the measured hardness value fits well to linear regression. 


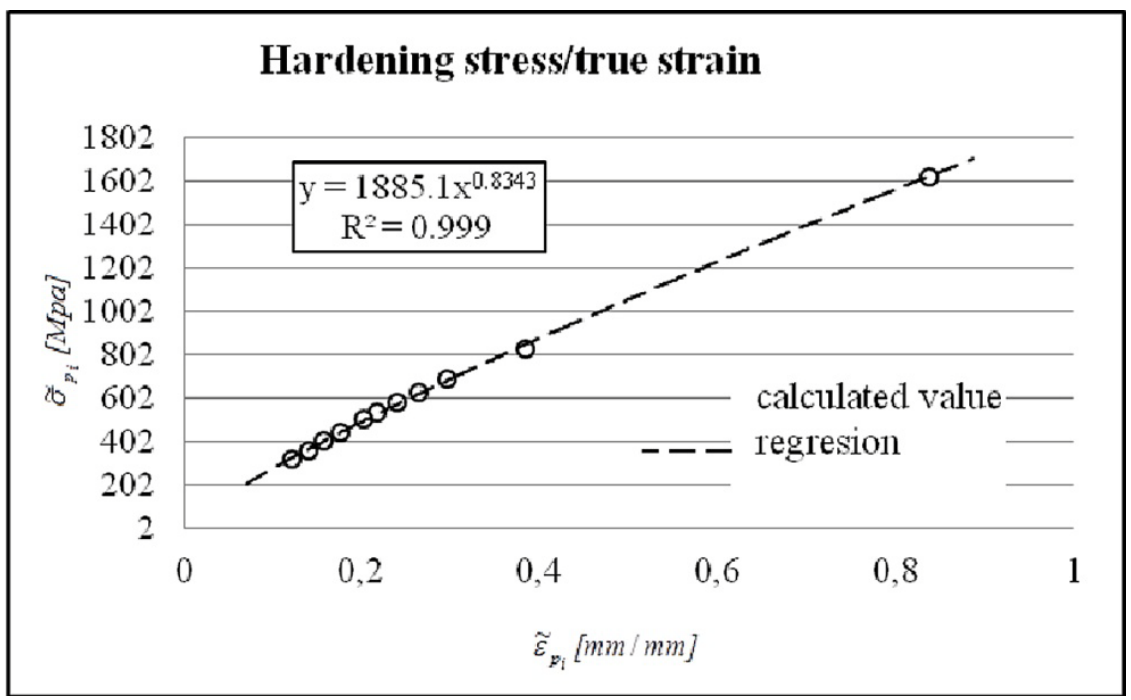

Figure 9. Hardening stress in function of the plastic component of the true strain curve for the specimen after tensile test

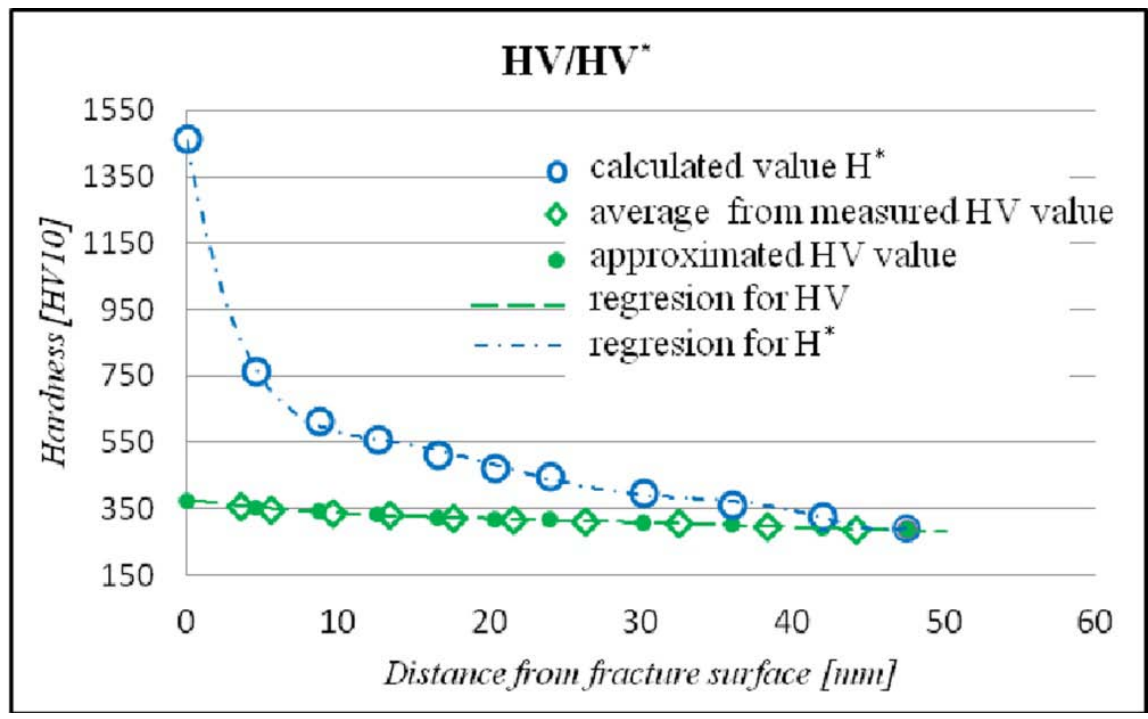

Figure 10. Hardness and reference hardness for tested Inconel 718

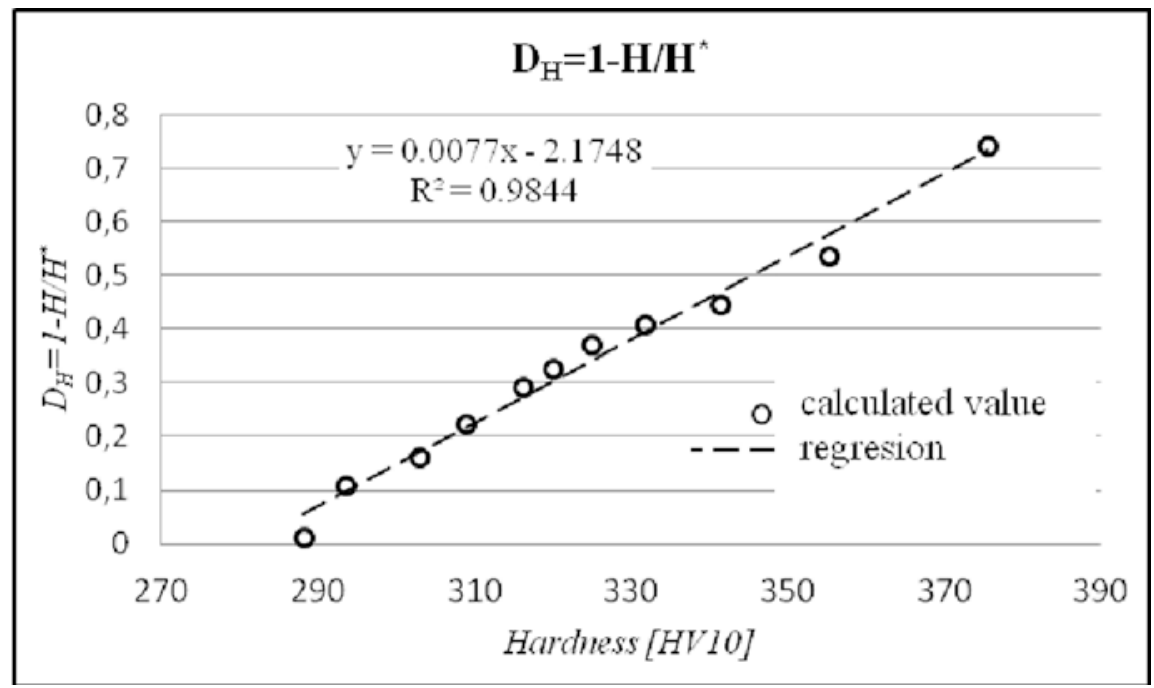

Figure 11. Damage parameter in relation to material hardness 
One disadvantage of evaluating the damage parameter based on hardness measurement is that hardness is not the material constant. It means that the value of $D_{H}$ will be dependent on a test method used. A more independent value of the damage parameter can be calculated based on the plastic strain value $\left(D_{\varepsilon}\right)$. It is possible to verify $D_{H}$ by comparing values of $D_{H}$ and $D_{\varepsilon}$.

\section{Correlation between $D_{\varepsilon}$ and $D_{H}$}

The damage parameter expressed by strains was defined by Jonson [9]. For the tensile test, $D_{\varepsilon}$ can be described by the equation:

$$
D_{\varepsilon}=\frac{\varepsilon_{p}}{\varepsilon_{p}^{f}}
$$

Where $\varepsilon_{p}$ is a variable value of equivalent plastic strain which occurs during tensile test, and $\varepsilon_{p}^{f}$ is strain equivalent to fracture.

Values obtained for $\varepsilon_{p}$ can range from 0 to $\varepsilon_{p}^{f}$. To evaluate the damage parameter defined by Equation (15) it was assumed that strain $\varepsilon_{p}^{f}$ is approximately equal to maximal strain which occurs in the neck of the fractured specimen. The Value of $\varepsilon_{p}$ in specimen reference sections $\left(\varepsilon_{p_{i}}\right)$ was calculated from the relation (Fig. 12):

$$
\varepsilon_{p_{i}}=-\left(\frac{a_{i}-a_{0}}{a_{0}}+\frac{b_{i}-b_{0}}{b_{0}}\right)
$$

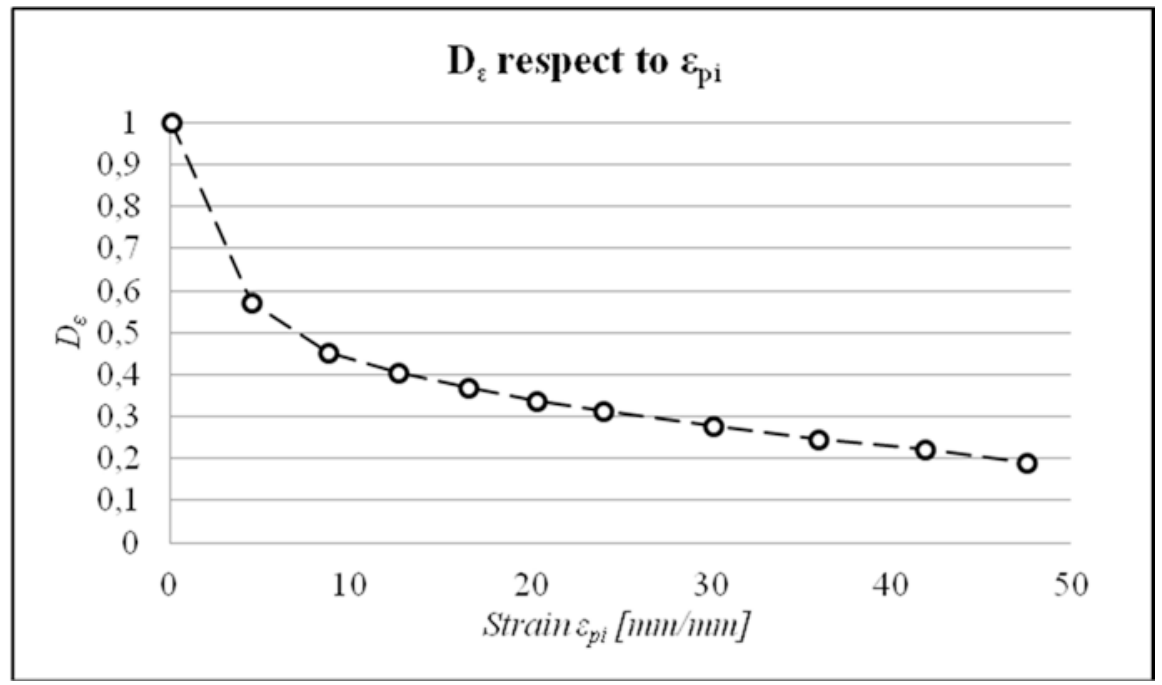

Figure 12. $D_{\varepsilon}$ in relation to $\varepsilon_{p i}$

As shown in Figure 13 the damage parameter calculated in relation to hardness doesn't match the damage parameter calculated with respect to tensile strain of the tested material. 


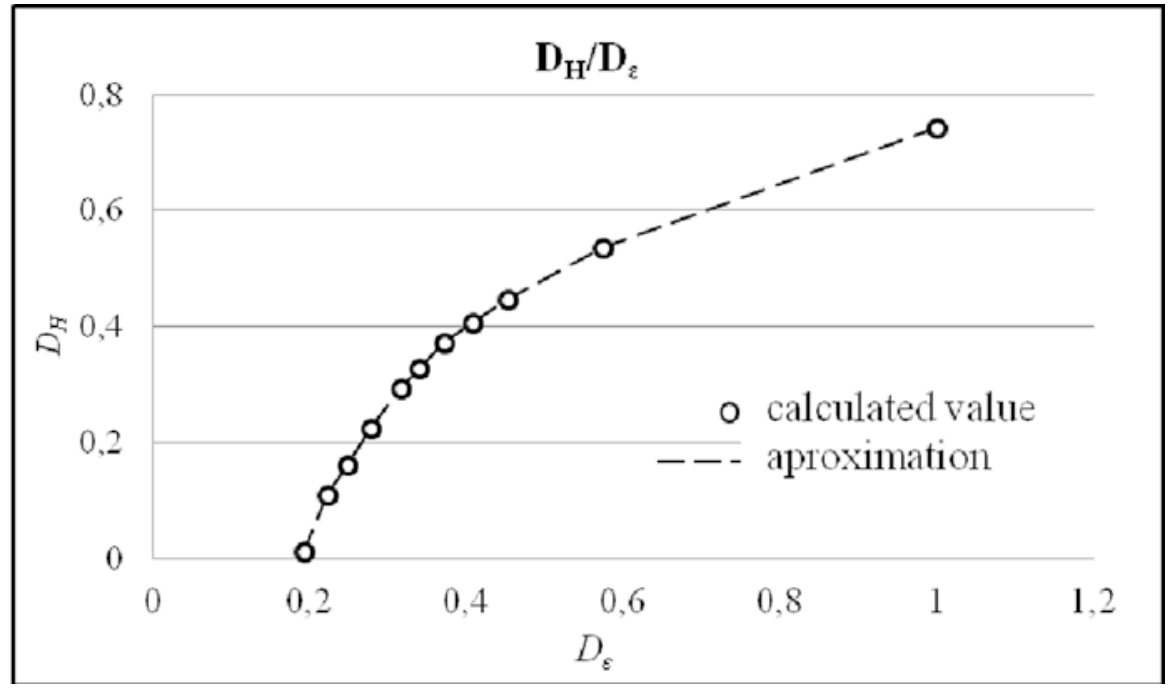

Figure 13. Correlation between $D_{\varepsilon}$ and $D_{H}$

One of the reasons why $D_{H}$ and $D_{\varepsilon}$ differ is the hypothetical value of $\mathrm{H}^{*}$. This value depends on the model used to describe strain hardening of the material in tensile test. Also it was assumed that $H$ and $H^{*}$ can be expressed as the linear function $\sigma_{\mathrm{s}}$. For a more independent value of $D_{H}$ the reference hardness can be taken as hardness in the virgin part of a piece of the material $\left(H^{\prime}\right)$ [10]. The damage parameter in that case $\left(D_{H^{\prime}}\right)$ will be expressed as:

$D_{H^{\prime}}=1-\frac{\sigma_{y} \cdot H_{\sigma_{u}}}{\sigma_{u} \cdot H^{\prime}}$

Where $\sigma_{u}$ is ultimate strain, $H_{\sigma_{u}}$ is hardness in the damaged part of a piece of the material, $\sigma_{\mathrm{u}}$ is ultimate stress.

The value of $D_{H}$, calculated in the same area of plastic strain as value of $D_{H}$ are lower (Figure 14) but better match the value of $D_{\varepsilon}$ (Figure 15).

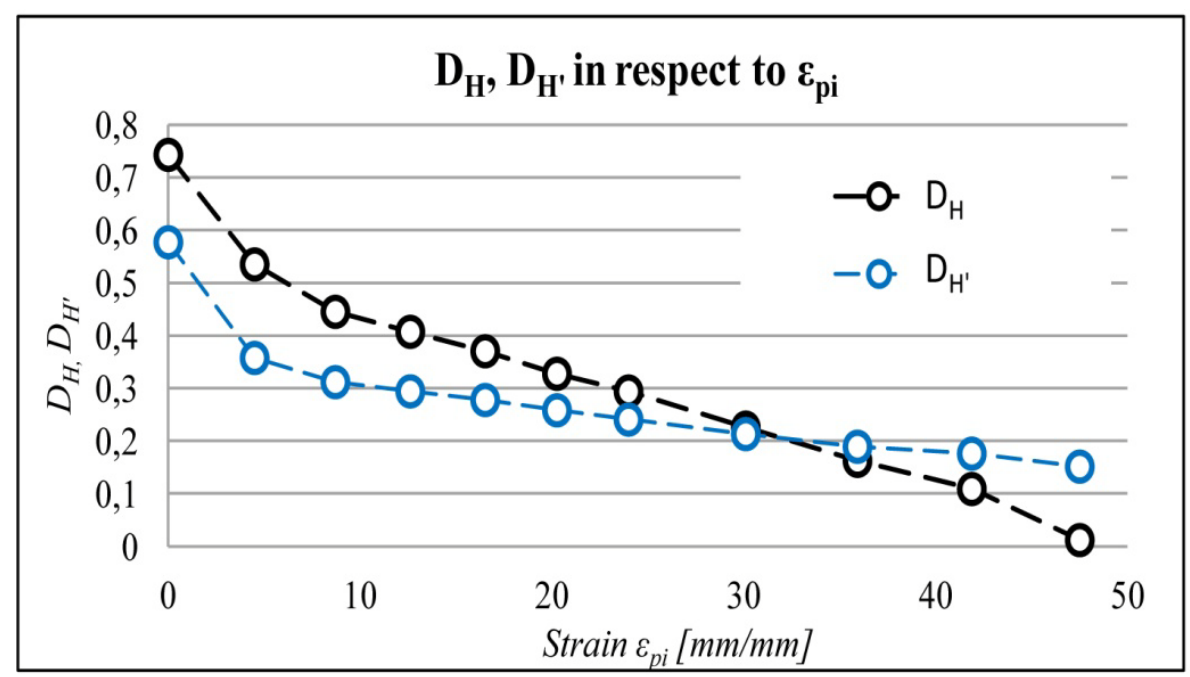

Figure 14. Damage parameter calculated form Equation (5) and (15) in relation to $\varepsilon_{p i}$ 


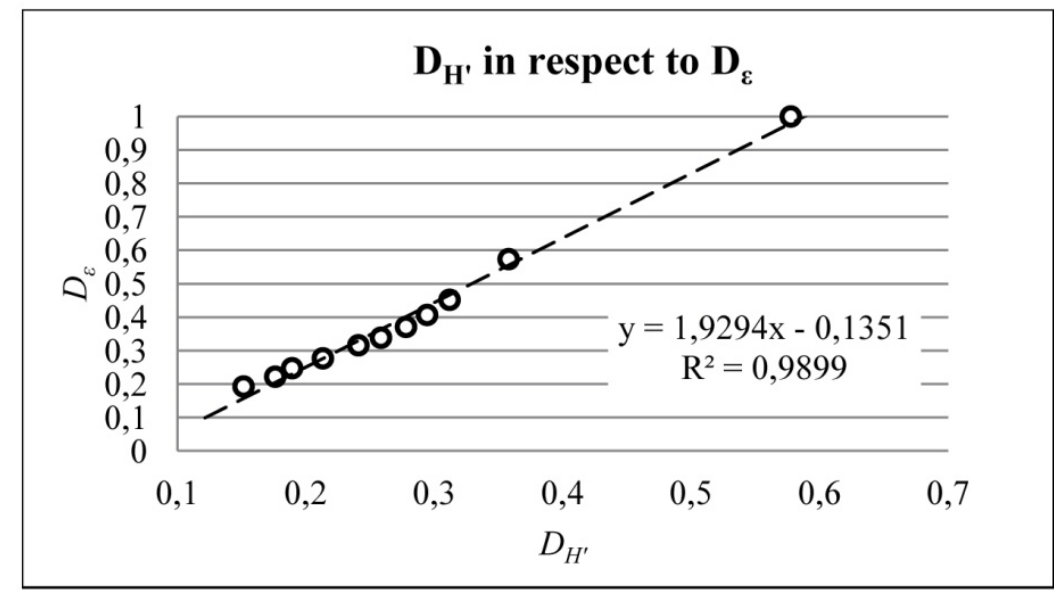

Figure 15. Correlation between $D_{\varepsilon}$ and $D_{H}$,

\section{SUMMARY AND CONCLUSIONS}

- It was shown that the hardness test can be a useful method to approximate the damage parameter $D_{\varepsilon}$.

- Damage related to debonding and cracking in NbC carbides doesn't change the trend of the material's hardness to increase with increasing the strain of tested Inconel 718.

- To obtain independent $D_{H}$ and $D_{H}$, from material strain hardening it is proposed to measure real hardness [11]. Real hardness measurement require annealing the material after the tensile test. For this reason there is no plastic hardening of the material and measured hardness should be more sensitive to material damage.

- Accuracy in determining $\sigma_{y}, \sigma_{u}$ and the true strain-true stress curve is very important. This is so because these data are used to calculate $D_{H}$. To increase this accuracy a new tensile test using an extensometer should be done. Tensile test should be performed on a specimen that has a regular cross section in the reduction area.

\section{ACKNOWLEDGMENTS}

The authors would like to express their acknowledgments to Grzegorz Socha and Józef Krysztofik for the opportunity to discuss the test results.

\section{REFERENCES}

[1] G.H. Majzoobia, F. Rahimi Dehgolan "Determination of the constants of damage model”, Procedia Engineering 10 (2011) 764-773.

[2] A. Mkaddem, R. Hambli, A. Potiron (2004). Comparison between Gurson and Lemaitre damage models in wiping die bending processes, Int J Adv Manuf Technol Vol. 23: 451-461.

[3] J. Lemaitre „A Course on Damage Mechanics”, Springer-Verlag Berlin Heidelberg in 1996.

[4] G. Socha, B. Madejski, J. Krysztofik, S. Czarnewicz “Test method of structural damages caused by permanent deformation of the alloy in the test sample by tensile test and the sample to test damage of the alloy structure", Patent pending no. P-409294, Urząd Patentowy RP.

[5] W. Zheng, X. Wei, Z. Song, Q Yong, H. Feng, Q. Xie "Effects off Carbon Content on Mechanical Properties off Inconel 718 Alloy", Journal Of Iron And Steel Research, International. 2015, 22(1):78-83. 
[6] M. Jutras "Improvement of the Characterisation Method of the Johnson-Cook Model”, FACULTÉ DES SCIENCES ET DE GÉNIE UNIVERSITÉ LAVAL QUÉBEC 2008.

[7] ASTM 384-11e1 "Standard Test Method for Knoop and Vickers Hardness of Materials".

[8] A. Mkaddem, R. Bahloul, P. Dal Santo, A. Potiron "Experimental characterisation in sheet forming processes by using Vickers micro-hardness technique”, Journal of Materials Processing Technology 180 (2006) 1-8.

[9] G. R. Johnson, W. H. Cook (1985). Fracture Characteristics of Three Metals Subjected to Various Strains, Strain Rates, Temperatures And Pressures, Engineering Fracture Mechanics Vol. 21, No. I, pp. 3148. 1985.

[10] Jean Lemaitre Rodrigue Desmorat „Engineering Damage Mechanics”, Springer-Verlag Berlin Heidelberg 2005.

[11] Tadeusz Pelczyński „The hardness of metals and alloys including the physics of plastic deformation” -monograph 2008; Polish. 